\title{
Age Differences in Women's Anger Experience and Expression
}

\author{
A. Antonio González-Prendes ${ }^{1}$, Nancy Praill ${ }^{1} \&$ Poco Kernsmith ${ }^{1}$ \\ ${ }^{1}$ School of Social Work, Wayne State University, Michigan, USA \\ Correspondence: A. Antonio Gonzalez-Prendes, School of Social Work, Wayne State University, 4756 Cass \\ Avenue \#308, Detroit, MI., 48202, USA. Tel: 1-313-577-5252. E-mail: aa3232@wayne.edu
}

Received: May 16, 2013 Accepted: June 7, $2013 \quad$ Online Published: August 15, 2013

doi:10.5539/ijps.v5n3p122 URL: http://dx.doi.org/10.5539/ijps.v5n3p122

\begin{abstract}
Research on women's anger is relative scarce. In this study the authors examined differences in anger experience and expression in women across three distinct age groups: 18-30, 31-49, and 50 and above. The authors used the State-Trait Anger Expression Inventory-2 (STAXI-2) to survey a sample of 239 women in the United States and Canada. The groups were established according to hypothesized transitional life stages of changing responsibilities and expectations. A MANCOVA was used to test the effect of age and covariates of education, employment, relationship status, and country of residence on participants' experience and expression of anger. The authors discuss limitations relative to sampling strategies as well as sample demographics and size, and discuss implications the implications of the findings for practice and future research.
\end{abstract}

Keywords: anger experience, anger expression, age differences, women's anger

\section{Introduction}

A number of authors have suggested that as people advance through the lifespan they are able to regulate their emotions and reactions to problems more effectively, become less aggressive and experience increased levels of well-being (Birditt, Fingerman, \& Almeida, 2005; Blanchard-Fields \& Cooper, 2004; Charles \& Carstensen, 2008; Charles \& Carstensen, 2009; Labouvie-Vief, Hakim-Larson, \& Hobart, 1987; Labouvie-Vief, Hakim-Larson, DeVoe, \& Schoeberlein, 1989; Phillips, Henry, Hosie, \& Milne, 2008; Stone, Schwartz, Broderick, $\&$ Deaton, 2010). However, very few researchers have examined how the experience and expression of anger in women may differ across various age groups (Hatch \& Forgays, 2001) as well as across various cultures or nationalities. Nonetheless, it has been suggested that emotional expression in general and anger expression in particular are influenced not only by age, but also by cultural norms and display rules that sanction the appropriate way of emotional expression within the culture (Adam, Shirako, \& Maddux, 2010; Konwar \& Ram, 2004; Matsumoto, Hee Yoo, \& Chung, 2010). Our purpose in this study was to assess differences in anger experience and expression in women across three distinct age groups, while controlling for covariates such as education, employment, relationship status, and the country of residence of the participants (i.e., United States or Canada).

The study of anger in women has received relatively little attention, compared to the study of other mental health concerns such as depression or anxiety (Thomas, 2005). Further illustrating this point, González-Prendes (2008) reported that, in a review of meta-analyses of empirical studies on anger treatment, which included a total of 148 separate studies, only two, both unpublished dissertations, focused exclusively on women as subjects. Yet, we argue, that specific information relative to the experience and expression of anger among women across the lifespan is important. Such data could inform the development of gender-specific, evidence-based treatments that can be tailored to address the particular needs of women. As it stands today, anger treatment generally focuses on male forms of anger expression and is centered on aggression as the problem. This perspective ignores available information which suggests that women express anger differently than men, and that long-standing cultural, societal and gender-role expectations discourage women from the direct and open expression of anger, leading women to view expression of anger as a threat to interpersonal relationships (Cox, Stabb, \& Bruckner, 1999; Cox, Van Velsor, \& Hulgus, 2004; Cox \& St. Clair, 2005; Hatch \& Forgays, 2001; Munhall, 1993; Sharkin, 1993; Thomas, 1989). Consequently, it seems that women suffer anger in silence, or maladaptively divert it to indirect means of expression which become transformed into other pathologies such as bulimia (Meyer et al., 2005), self-cutting (Abu-Madini \& Rahim, 2001; Matsumoto et al., 2004) and substance abuse (Gilbert, Gilbert, \& Schultz, 1998; Larimer, Palmer, \& Marlatt, 1999) or health problems, such as hypertension, coronary heart disease (Kamarck et al., 2009; Warren-Findlow, 2006; Webb \& Beckstead, 2005) or obesity (Ricca et al. 2009; 
Robert \& Reither, 2004).

\subsection{Theoretical Background: Emotional Expression across the Lifespan}

There is a dearth of information regarding age differences in the experience and expression of anger in women, and few researchers have compared anger responses in women across the lifespan. Those that have looked at this issue report mixed or inconclusive results. Hatch and Forgays (2001) studied differences in responses to anger-provoking situations between older adolescents and adult females. In a sample of 281 women (163 younger students; 118 older office employees) the authors reported that the younger group of students reported a greater likelihood of experiencing and expressing anger than did the older office employees. However, it was suggested that work status, rather than life development, may have been a better predictor for anger expression, although not for anger experience (Hatch \& Forgays). Although there is a paucity of studies that have examined the experience and expression of anger across the lifespan in women, some authors have assessed anger within the wider spectrum of emotional expression in mixed samples of men and women. Phillips, Henry, Hosie and Milne (2006) used a mixed sample $(n=286)$ of men and women ranging in age from 18 to 88 to investigate age differences in anger regulation, and whether these differences could be explained by social desirability effects. The researchers indicated that age was significantly negatively correlated with trait anger and anger expression measures, and significantly positively correlated with anger control measures. Phillips et al. (2006) concluded that their data revealed that the majority of the effects of age on anger were not related to variance in social desirability of responding. In another study Thomas (2002) evaluated a mixed non-clinical sample of 206 men and 189 women and reported that there were few age differences in anger frequency, intensity, and expression. One point of interest in Thomas' study was that women in their 40's had significantly higher levels of anger in the workplace than did women in other age groups, and measured almost twice as high as those of men. On the other hand, Charles and Carstensen (2008) compared differences in emotional responses to unpleasant situations in a mixed sample of younger and older men and women, and indicated that older adults reported lower levels of anger than did their younger counterparts. Some have suggested that older adults are more adept at "picking their battles" and reporting fewer interpersonal conflicts, while responding to the conflicts they do encounter with less stress and better emotional regulation (Alea et al., 2004; Birditt \& Fingerman, 2005; Birditt et al., 2005; Charles \& Carstensen, 2008; Mroczek \& Almeida, 2004). It has also been suggested that older adults address interpersonal problems with more passive, emotion-focused strategies, such as avoidance and passive-dependence (Blanchard-Fields, Mienaltowski, \& Seay, 2007; Minick \& Gueldner, 1995). Mroczek and Kolerz (1998) examined the effects of age on positive and negative affect and found that, while positive affect was associated with age in women in a nonlinear fashion, there was no association between age and negative affect. In another study Mroczek (2001) suggested that the relationship between positive emotions and age is curvilinear, with an increase in positive emotions throughout adulthood and into the early years of old age, but then tapering off during the oldest years, as individuals struggle with declining health. Conversely, Carstensen, Pasupathi, Mayr, and Nesselroade (2000), while exploring age differences in emotional experience across the lifespan, reported that there is a steady decrease in negative emotional experience from 18 to about 60 years of age, at which time the decrease stops and there is a slight and non-significant upward trend in negative emotional experience. We suggests that the common wisdom, derived from the available information, supports the idea that as individuals get older they seem to experience less negative emotions, become more adept at regulating emotion, and improve their ability to effectively choose which battles to fight.

Nonetheless, one thing is clear, when it comes to the issue of women and anger: more research is needed to shed a light on critical variables (i.e., age) and processes that affect the experience and expression of anger in women. Certainly, more information is needed regarding the experience and expression of anger in women across the lifespan. On this point, we must make the distinction that, for women, expressing negative emotions such as sadness does not carry the same social implications and ramifications as expressing anger. Although some authors (Averill, 1982; Fischer et al, 1993) have suggested that there are no differences in either the propensity or frequency of anger expression between women and men, there seem to be differences in the manner in which anger is expressed by the genders. It has been suggested that the manner of anger expression in women is shaped by gender socialization patterns that discourage the open and direct expression of anger, and lead women to view such anger expression as a threat to interpersonal relationships (Cox, Van Velsor, \& Hulgus, 2004; Hatch \& Forgays, 2001; Munhall, 1993; Sharkin, 1993; Thomas, 1989). Consequently, when it comes to anger expression women may avoid awareness of the angry feelings and/or divert them into indirect forms of expression (Cox et al., 1999; Cox et al., 2004; Cox \& St. Clair, 2005).

\subsection{Anger and Culture}

It has been suggested that across cultures anger is subject to culturally-sanctioned norms and display that 
underscore the appropriate way experience and express anger within a particular culture (Adam et al., 2010; Konwar \& Ram, 2004; Matsumoto et al., 2010). Although such cultural and societal norms may vary from country to country, expressions of anger with some modifications and variability can be found across cultures (Matsumoto, et al., 2010). The concept of anger has (1) universal aspects that cut across cultures (e.g., metaphors used to describe anger) as well as (2) culture-specific elements (e.g., the prototypical models for venting anger) (Kövecses, 2000; 2010). For example, some authors have suggested that across cultures anger is regarded as a divisive and disruptive force leading to social disorganization and intragroup aggression (Potegal \& Novaco, 2010; Matsumoto et al., 2010). On the other hand, expressions of anger have been found to be influenced by whether a particular culture adheres primarily to a collectivistic or individualistic perspective. For instance, Potegal and Novaco (2010) assert that the display rules in societies that focus on a collectivist perspective, and thus place greater value on interdependence and maintaining social harmony (e.g., Asian groups), are less likely to sanction the overt and direct expression of anger. Conversely, societies with a more individualistic and egalitarian perspective that place greater value on independence and self-determination (e.g., Western groups), are more likely to sanction the open and direct expression of angry feelings. However, it remains that across cultures the direct and overt expression of anger seems to be primarily the domain of men (Matsumoto et al., 2010; Potegal \& Novaco, 2010); and thus women are not expected to express their anger openly and directly. Although in this study we did not assess differences in anger experience and expression across various cultures, we investigated whether there were any differences in the women's experience and expression of anger according to "country of residence' (i.e., United States or Canada).

\section{Method}

\subsection{Procedure}

The authors conducted an exploratory and descriptive evaluation of age differences in anger experience and expression in a sample of 239 women. The statistical analysis was conducted using IBM Statistical Package for Social Sciences-version 19. The authors conducted the study entirely online. Those individuals who were interested in participating were asked to contact a website at which they received a code, allowing them entry to the test site. The procedure included the completion of a demographics questionnaire; reading a brief vignette depicting an interpersonal conflict (see Appendix); and completing the State-Trait Anger Expression Inventory-2 (STAXI-2, Spielberger, 1999). Participants completed the STAXI-2 after reading the vignette. Informed consents were obtained. The researchers received full approval for this study from the university's Institutional Review Board.

\subsection{Participants}

For this study we recruited participants in the United States and Canada through advertisements placed on local universities' websites and Blackboard systems, and using flyers that were distributed at local agencies, organizations and clubs. A total of 240 women responded, but one individual did not provide her age, and was therefore excluded. The final sample consisted of 239 women. The women ranged in age from 18 to $75(\mathrm{M}=37$, $\mathrm{SD}=13.26$ ). Fifty-five percent of the women indicated that they were either married or in relationship, $44.4 \%$ were not married, and $.08 \%$ did not provide a response. Of the 239 women, 117 (49\%) declared Canada as their current country of residence and $122(51 \%)$ indicated that they resided in the United States. The sample was overwhelmingly white (83\%) with 7.5\% African American, 4.2\% Asian, and 5.3\% other groups including Hispanic, Native American, and various Middle Eastern groups. Participants were asked to designate their highest level of educational attainment, and the responses were: graduate school $(18.8 \%)$, some graduate school $(14.23 \%)$, college $(37 \%)$, some college $(23.4 \%)$, high school or equivalent $(6.3 \%)$, and some high school $(.042 \%)$. Regarding religious affiliation, $32.2 \%$ of participants described themselves as Christians (non-Catholic), 29.3\% Catholic, 22.6\% Agnostic/Atheist, 4.2\% Spiritual, 2\% Jewish, 1.7\% Muslim, 2.9\% "other". Five percent of participants did not declare any religious identification. Most of the participants were employed either full-time (44.4\%) or part-time (29.3\%); $20 \%$ of participants reported not being employed outside the home; and $6.7 \%$ did not respond to that question.

\subsection{Age Groups}

In order to evaluate age differences, we divided the sample into three groups. The younger group $(\mathrm{n}=96)$ consisted of women ranging in age from 18 to 30 years old $(\mathrm{M}=24.8, \mathrm{SD}=3.09)$. The middle group $(\mathrm{n}=94)$ included women from 31 to 49 years of age $(M=37.9, S D=4.53)$. The older group $(n=49)$ was made up of women with an age range from 51 to 75 years old $(\mathrm{M}=58.7, \mathrm{SD}=5.75)$.

When deciding on the age parameters for each group, rather than focusing on a chronological divisions of life stages solely defined by age (e.g., 20-29, 30-39, 40-49, etc.), we were interested in looking at transitional divides 
that may signify qualitative differences between the stages with shifts in responsibilities and challenges, societal expectations, new stressors, role changes, and perhaps a change in perspective or way of coping. For this purpose we looked at two specific theories, Levinson's theory of life structure (Levinson, 1978; Levinson \& Levinson, 1996), and Arnett's theory of emerging adulthood (2000, 2004). Levinson's theory (1978) identifies two key life transitional points occurring at ages 30 and 50 that mark significant changes in life trajectory and structure. According to Mitchell (2011) it is not unusual for people to drift and experiment during their 20's while searching for their life trajectory, but she also suggests that by the early thirties most people have charted the course of their lives and made commitments to work and relationships. The period of development from the late teens through the twenties, prior to age 30, corresponds to what Arnett refers to as "emerging adulthood". Arnett suggests that this stage in the lifespan is characterized by identity exploration and some instability regarding relationships, education, work and career. Arnett further suggests that, even though there is considerable variation in the path that people take to adulthood, most people see age 30 as the point at which they believe they have reached adulthood; and are facing multiple commitments and responsibilities. While the period prior to age 30 may be characterized by drifting, exploration and experimentation, the decades of the thirties and forties seem to be characterized by increased expectations, responsibilities, personal and professional challenges and the adaptations and demands associated with these. While discussing Levinson's theory, Hattar-Polara (2010) suggests that, during the decade of the thirties, people generally establish their niche in society and begin to settle down, while facing more demanding roles and expectations. The roles and expectations at this stage of development seem to be qualitatively different from the roles and expectations that the individual might have faced in her twenties, as women have either started to focus on or are settling into their careers, relationships, and families, and are facing the associated responsibilities, demands, and stresses. Some of the stressors that women may face in this stage of life (i.e., 30's and 40's) include caring for children as well as for aging parents, broken relationships and divorce, career/employment challenges or changes, and emerging health concerns, among others. According to Hattar-Polara, (2010) the stresses of the thirties may evolve into a crisis in the forties rooted in questions about the meaning, value, and direction of life. Along these lines, Stevenson (as quoted in Thomas, 2002, p. 49) describes part of this stage as a "mid-40s inferno... when stability comes crashing down, and many people in their middle forties find themselves in a terrific struggle with themselves, their significant other, and the world at large". For some, the decades of the thirties and forties may represent increased changes and turmoil in their lives. Toward the end of the 40's or around age 50, people are faced with another transitional point (Levinson, 1978; Levinson \& Levinson, 1996). Mitchell (2011) suggests that, as we approach late adulthood, we begin to adopt a different perspective towards family and work. For many women at this stage, the children are grown and they no longer see themselves as building a career. Therefore, the expectations and stressors associated with work and parenting may diminish. Although other stressors may emerge (e.g., increased health problems), some authors have suggested that as people get older they perhaps learned to adapt to the stressors of life and become more adept at choosing which battles to fight (Birditt \& Fingerman, 2005; Minick \& Gueldner, 1995). Therefore, we expected that relative to our sample the older group (50 and above) would demonstrate lower levels of anger experience and expression followed by the middle group (31-49) and then the younger group ( 30 and below).

\subsection{Instrument}

\subsubsection{State-Trait Anger Expression Inventory-2 (STAXI-2, Spielberger, 1999)}

The STAXI-2 (Spielberger, 1999) is a 57-item instrument that has been widely used in clinical practice and research for the evaluation of anger. It measures the experience, expression and control of anger. It consists of 6 scales (i.e., state anger, trait anger, anger expression-out, anger expression-in, anger control-out, and anger control-in); 5 subscales (feeling angry, feel like expressing anger verbally, feel like expressing anger physically, angry temperament, and angry reaction); and an overall anger expression index. STAXI-2 normative data derived from female populations indicate alpha coefficients of internal consistency ranging from .74 (anger expression-out) to .93 (anger control-in), and subscales ranging from .76 (anger reaction) to .88 (feel like expressing anger verbally) (Spielberger, 1999).

Spielberger (1999) defines "state anger" as the intensity of a person's angry feeling and the degree to which a person feels like expressing anger at any particular moment. State anger (S-Ang) tends to arise as a response to a specific situation that the person deems to be anger-provoking. There are three subscales of the S-Ang scale: Feeling Angry (S-Ang/F) which measures the intensity of current angry feelings; Feel Like Expressing Anger Verbally (S-Ang/V) which focuses on the intensity of current anger related to its verbal expression; and Feel Like Expressing Anger Physically (S-Ang/P) which focuses on the intensity of physical expression of anger.

According to Spielberger (1999), the trait anger scale (T-Ang) measures the frequency with which one 
experiences angry feelings over time. Individuals with high levels of trait anger may find themselves responding with higher intensity of state anger to a wide range of situations. Two subscales of the T-Ang scale are: Angry Temperament (T-Ang/T) which measures the individual's propensity to react angrily without specific provocation, and Angry Reaction (T-Ang/R) which measures the frequency with which the person experiences anger in situations that are frustrating or involve evaluations.

Regarding the anger control scales, Anger Control-Out (AC-O) measures the frequency with which a person attempts to control the outward expression of anger, and Anger Control-In (AC-I) measures how often a person tries to control anger by calming down or cooling off (Spielberger, 1999). Anger expression includes two scales: Anger Expression-Out (AX-O) measures how frequently anger is expressed through either physical or verbal aggression; and Anger Expression-In (AX-I) measures how frequently the person suppresses the experienced angry feelings. The anger expression index (AX Index) is an overall indicator of anger expression based on the individual's responses to the anger control and anger expression scales (Spielberger, 1999).

\subsection{Hypotheses}

The null hypotheses for the study are as follows:

$\mathrm{H}_{\mathrm{o}} 1$. State anger and trait anger categories will not differ significantly by age group, after controlling for education, employment, relationship status, and country of residence.

$\mathrm{H}_{0} 2$ Anger expression-out scores will not differ significantly by age group, after controlling for education, employment, relationship status, and country of residence.

$\mathrm{H}_{0} 3$. Anger expression-in scores will not differ significantly by age group, after controlling for education, employment, relationship status, and country of residence.

$\mathrm{H}_{\mathrm{o}} 4$. Anger control scores will not differ significantly by age group, after controlling for education, employment, relationship status, and country of residence.

\subsection{Data Analysis}

We used a one-way multivariate analysis of covariance (MANCOVA), with age as the fixed factor and education, employment, relationship status, and country of residence data used as covariates to investigate the extent to which differences in participants' experience and expression of anger were influenced by age categories. Statistical analyses were evaluated at an alpha level of .05.

\section{Results}

The mean scores for each of the three age groups for the scales and subscales of the STAXI-2 are presented in Table 1.

Table 1. STAXI-2 scores

\begin{tabular}{llll}
\hline & Younger Group & Middle Group & Older group \\
& $\mathrm{N}=96$ & $\mathrm{~N}=94$ & $\mathrm{~N}=49$ \\
& Mean $(\mathrm{SD})$ & Mean $(\mathrm{SD})$ & Mean $(\mathrm{SD})$ \\
\hline State anger & $17.98(4.22)$ & $18.70(7.54)$ & $16.35(4.50)$ \\
S-Ang/F & $6.93(2.35)$ & $6.93(2.86)$ & $5.82(2.39)$ \\
S-Ang/V & $5.78(1.75)$ & $6.30(3.32)$ & $5.41(1.64)$ \\
S-Ang/P & $5.27(0.98)$ & $5.48(2.03)$ & $5.12(0.60)$ \\
Trait anger & $19.59(5.37)$ & $19.76(5.49)$ & $18.45(5.90)$ \\
T-Ang/T & $6.97(2.80)$ & $7.26(2.66)$ & $6.29(2.64)$ \\
T-Ang/R & $9.35(2.64)$ & $9.02(2.78)$ & $8.92(2.79)$ \\
AC-O & $22.44(4.81)$ & $21.52(4.73)$ & $23.73(4.23)$ \\
AC-I & $22.25(5.01)$ & $22.28(5.39)$ & $23.22(2.52)$ \\
AX-O & $15.96(3.96)$ & $16.46(3.82)$ & $14.71(4.08)$ \\
AX-I & $19.03(4.80)$ & $18.05(5.08)$ & $17.84(4.94)$ \\
AX-Index & $38.30(12.96)$ & $38.71(12.49)$ & $33.59(13.84)$ \\
\hline
\end{tabular}

Mean scores and standard deviations for all scales and subscales of the STAXI-2 for each group.

The Levene test for equality of variance revealed that equal variances could be assumed for the groups, except in relation to scores of the state-anger scale and its subscales (see Table 2). 
Table 2. Levene's test of equality for error variances

\begin{tabular}{lllll}
\hline & $\mathrm{F}$ & $\mathrm{df1}$ & $\mathrm{df} 2$ & Sig. \\
\hline State anger & 5.984 & 2 & 236 & $.003^{*}$ \\
S-Ang/F & 4.335 & 2 & 236 & $.014^{*}$ \\
S-Ang/V & 8.043 & 2 & 236 & $.000^{*}$ \\
S-Ang/P & 4.192 & 2 & 236 & $.016^{*}$ \\
Trait anger & 0.06 & 2 & 236 & .994 \\
T-Ang/T & .354 & 2 & 236 & .703 \\
T-Ang/R & .292 & 2 & 236 & .747 \\
AC-O & .817 & 2 & 236 & .443 \\
AC-I & .789 & 2 & 236 & .456 \\
AX-O & .051 & 2 & 236 & .950 \\
AX-I & .174 & 2 & 236 & .840 \\
AX Index & .323 & 2 & 236 & .724 \\
\hline
\end{tabular}

$* \mathrm{p}<.05$, equal variance cannot be assumed.

Some authors have suggested that, when the test for equality of variance yields significant results and group sample sizes are unequal, as happened in this study (i.e., younger $[n=96]$, middle $[n=94]$, older [ $n=48]$ ), a more robust multivariate test statistic, such as Pillai's Trace, should be used to interpret the results of the MANCOVA (Mertler \& Vanatta, 2005; Tabachnick \& Fidell, 1996). The MANCOVA revealed no significant relationship between any of the covariates of education, employment, relationship status, and country of residence and the dependent variables (see Table 3). However, there was a significant interaction for "age" (Pillai's Trace $=.151, \mathrm{~F}[20,448]=1.82, \mathrm{p}<0.05$, partial $\eta 2=.075)$. The observed power was .976 .

Table 3. Results of MANCOVA

\begin{tabular}{llccc}
\hline & $\begin{array}{l}\text { Pillai's Trace } \\
\text { Sig./Partial } \eta 2 / \\
\text { Observed Power }\end{array}$ & $\begin{array}{l}\text { Wilk's Lambda } \\
\text { Sig./Partial } \eta 2 / \\
\text { Observed Power }\end{array}$ & $\begin{array}{l}\text { Hotteling's Trace } \\
\text { Sig./Partial } \eta 2 / \\
\text { Observed Power }\end{array}$ & $\begin{array}{l}\text { Roy Largest Root } \\
\text { Sig./Partial } \eta 2 / \\
\text { Observed Power }\end{array}$ \\
\hline Intercept & $.000 / .742 / 1.000$ & $.000 / .742 / 1.000$ & $.000 / .742 / 1.000$ & $.000 / .742 / 1.000$ \\
Education & $.181 / .059 / .702$ & $.181 / .059 / .702$ & $.181 / .059 / .702$ & $.181 / .059 / .702$ \\
Employment & $.468 / .042 / .508$ & $.468 / .042 / .508$ & $.468 / .042 / .508$ & $.468 / .042 / .508$ \\
Relationship & $.341 / .048 / .585$ & $.341 / .048 / .585$ & $.341 / .048 / .585$ & $.341 / .048 / .585$ \\
Country of & $.745 / .029 / .351$ & $.745 / .029 / .351$ & $.745 / .029 / .351$ & $.745 / .029 / .351$ \\
Residence & $.016 * / .075 / .976$ & $.017 * / .075 / .976$ & $.018 * / .075 / .975$ & $.031 * / .083 / .882$ \\
Age & & &
\end{tabular}

$* p<.05$. Age has a significant effect on dependent variables. Covariates "education", "employment", "relationship", and "country of residence" have not significant effect on the dependent variables.

Given the significance of the overall test, univariate tests of between-subjects effects (see Table 4) indicated that age had significant interactions with T-Ang/T $(\mathrm{F}[2,232]=3.49, \mathrm{p}<.05$, partial $\eta 2=.029$, power $=.648)$; S-Ang $(\mathrm{F}[2,232]=3.68, \mathrm{p}<.05$, partial $\eta 2=.031$, power $=.672) ; \mathrm{S}-\mathrm{Ang} / \mathrm{F}(\mathrm{F}[2,232]=5.36, \mathrm{p}<.05$, partial $\eta 2$ $=.044$, power $=.840)$; AC-O $(\mathrm{F}[2,232]=4.16, \mathrm{p}<.05$, partial $\eta 2=.035$, power $=.730)$; AX-O $(\mathrm{F}[2,232]=$ $3.75, \mathrm{p}<.05$, partial $\eta 2=.031$, power $=.682)$. 
Table 4. Univariate tests of between-subjects effects

\begin{tabular}{llllllll}
\hline & $\begin{array}{l}\text { Sum of } \\
\text { squares }\end{array}$ & df & $\begin{array}{l}\text { Mean } \\
\text { squares }\end{array}$ & F & Sig. & Partial $\eta 2$ & $\begin{array}{l}\text { Observed } \\
\text { power }\end{array}$ \\
\hline T-Ang/T & 49.55 & 2 & 24.77 & 3.49 & $.032^{*}$ & .029 & .648 \\
S-Ang & 245.31 & 2 & 122.66 & 3.68 & $.027^{*}$ & .031 & .672 \\
S-Ang/F & 69.44 & 2 & 34.73 & 5.36 & $.005^{*}$ & .044 & .840 \\
AC-O & 180.21 & 2 & 90.10 & 4.16 & $.017^{*}$ & .035 & .730 \\
AX-O & 115.71 & 2 & 57.86 & 3.75 & $.025^{*}$ & .031 & .682 \\
\hline
\end{tabular}

$* \mathrm{p}<.05$.

We further conducted pairwise comparisons using the Bonferroni test to identify significant differences among the three age groups (see Table 5).

Table 5. Pairwise comparisons with Bonferroni test

\begin{tabular}{llll}
\hline & Mean difference & Standard error & Sig. \\
\hline $\begin{array}{l}\text { T-Ang/T } \\
\text { Older vs. middle }\end{array}$ & 1.22 & .479 & $.035^{*}$ \\
$\begin{array}{l}\text { S-Ang } \\
\text { Older vs. middle }\end{array}$ & -2.76 & 1.04 & $.026^{*}$ \\
S-Ang/F & & $.006^{*}$ \\
$\quad \begin{array}{l}\text { Older vs. younger } \\
\text { Older vs. middle }\end{array}$ & -1.46 & .467 & $.020^{*}$ \\
AC-O & -1.25 & .458 & $.022^{*}$ \\
$\quad$ Older vs. middle & 2.27 & .836 & $.021^{*}$ \\
AX-O & & .706 & \\
Older vs. middle & -1.93 &
\end{tabular}

${ }^{*} \mathrm{p}<.05$. Scores demonstrate where the significant differences are between the three groups.

Regarding T-Ang/T, the middle group $(\mathrm{M}=7.26, \mathrm{SD}=2.66)$ had significantly higher scores than the older group $(\mathrm{M}=6.29, \mathrm{SD}=2.64)$. $\mathrm{S}$-Ang scores revealed that the middle group $(\mathrm{M}=18.70, \mathrm{SD}=7.54)$ scored significantly higher than the older group $(\mathrm{M}=16.35, \mathrm{SD}=4.50)$. On $\mathrm{S}-\mathrm{Ang} / \mathrm{F}$, the younger $(\mathrm{M}=6.93, \mathrm{SD}=2.35)$ and middle $(\mathrm{M}=6.93, \mathrm{SD}=2.86)$ groups had significantly higher scores than the older group $(\mathrm{M}=5.82, \mathrm{SD}=2.39)$. On the AC-O scale, the older group $(\mathrm{M}=23.73, \mathrm{SD}=4.23)$ scored significantly higher that the middle group $(\mathrm{M}=$ $21.52, \mathrm{SD}=4.73)$. Regarding AX-O, the middle group's scores $(\mathrm{M}=16.46, \mathrm{SD}=3.82)$ were significantly higher than the older group $(\mathrm{M}=14.71, \mathrm{SD}=4.08)$.

\section{Discussion}

We surveyed 239 women between the ages of 18 and 75 to assess whether three distinct age categories had a significant effect on various aspects of anger experience and expression, after controlling for participants' education level, employment status, relationship status, and country of residence. The participants' experience and expression of anger were measured by the STAXI-2 (Spielberger, 1999). We used a multivariate analysis of covariance to evaluate the effects of age, with three levels, on the dependent variables (i.e., scales and subscales of STAXI-2) while controlling for covariates. Participants were divided into three age groups: younger [30 and under], middle [31-49 years old], and older [50 and over] based on hypothesized transitional points and lifespan stages that may bring varying levels of responsibilities, societal expectations, and life stressors. Participants were asked to complete a brief demographic questionnaire and to read a brief vignette that depicted an interpersonal conflict before they completed the survey. 
Overall, the results of the analysis indicate significant differences between the groups in the areas of angry temperament (T-Ang/T), state anger (S-Ang), feeling angry (S-Ang/F), anger expression-out (AX-O), and anger control-out (AC-O). In the category of angry temperament (T-Ang/T), the middle group's scores $(\mathrm{M}=7.26, \mathrm{SD}$ $=2.66)$ were significantly higher than the older group, $(\mathrm{M}=6.29, \mathrm{SD}=2.64)$ suggesting that, at the time of the study, the middle group, when compared to the older group, might have been more likely to experience anger without provocation. The middle group $(\mathrm{M}=18.70, \mathrm{SD}=7.54)$ also had significantly higher scores in the state anger scale ( $\mathrm{S}-\mathrm{Ang}$ ) than the older group $(\mathrm{M}=16.35, \mathrm{SD}=4.50)$ suggesting that, at the time that they completed the survey, the participants in the middle group had experienced higher intensity of angry feelings and were more likely to convey those feelings than were the participants in the older group (Spielberger, 1999). The middle group $(\mathrm{M}=6.93, \mathrm{SD}=2.86)$ and the younger group $(\mathrm{M}=6.93, \mathrm{SD}=2.35)$ were also statistically higher in their scores on state-anger frequency $(\mathrm{S}-\mathrm{Ang} / \mathrm{F})$ compared to the older group $(\mathrm{M}=5.82, \mathrm{SD}=2.39)$. This finding suggests that at the time of the survey the middle and younger groups were experiencing higher intensity of angry feelings, compared to the older group. We also found significant differences between the older and middle groups in measures of anger control-out (AC-O). Participants in the older group ( $\mathrm{M}=23.73, \mathrm{SD}=4.23)$ scored significantly higher than those in the middle group $(\mathrm{M}=21.52$, $\mathrm{SD}=4.73)$. These scores suggest that the participants in the older group were more apt to monitor and to not express angry feelings than participants in the middle group. A final significant finding was also revealed in the scale of anger expression-out (AX-O). In this scale, the middle group $(\mathrm{M}=16.46, \mathrm{SD}=3.82)$ scored significantly higher than the older group $(\mathrm{M}=14.71, \mathrm{SD}$ $=4.08$ ). According to Spielberger (1999), the middle group's higher scores suggest that these participants, when compared to the older group, were more likely to express their anger in either verbally and/or physically aggressive ways. There were no significant differences in this category between the younger and either the middle or older groups.

Besides the statistically significant differences already discussed, the analysis of the data reveals some other outcomes worth noting. It has been suggested that, younger adults, in response to interpersonal conflicts, are more likely to experience anger than older adults (Charles \& Carstensen, 2008). It has also been suggested that older adults tend to report fewer interpersonal conflicts and respond to those with less stress and better emotional regulation (Alea, Bluck, Smegon, 2004; Birditt \& Fingerman, 2005; Birditt, Fingerman, \& Almeida, 2005; Charles \& Carstensen, 2008; Mroczek \& Almeida, 2004). As regards to this sample of women, our results would seem to partially support that proposition. In our sample the older group had the lowest scores for all scales and subscales of the STAXI-2, except for the anger control scales, AC-O and AC-I, in which they had the highest scores. One could argue that having the highest scores in the anger control scales could be a result of either being less affected by the interpersonal aspect of the vignette (i.e., participants were not equally impacted by the content of the vignette) or increased ability to regulate one's emotions (i.e., learning to pick one's battles). In our sample the decreases in state and trait anger and anger expression categories held true for the older group, but not for the middle one. Moreover, our findings also partially echo Phillips, Henry, Hosie, \& Milne (2006) who reported that, in sample of 286 men and women, age was negatively correlated with all subscales of the STAXI-2, except for AC-O and AC-I. As Carstensen, Pasupathi, Mayr, and Nesselroade (2000) have suggested, there is a decrease in negative emotional experience from ages 18 to about 60 . We expected to see a steady decrease in anger experience and expression from the younger through the middle and then to the older group. However, we found that the middle group (women between the ages of 31 and 49), and not the younger group (women 30 years of age or younger), produced the highest scores in S-Ang, S-Ang/F (tied with the younger group), S-Ang/V, S/Ang/P, T-Ang, T-Ang/T, AX-O, and AX-Index, and the lowest scores in AC-O (see Table 1). Additional research would be needed to evaluate whether this pattern would hold with other samples of women and with different age parameters. Perhaps structuring this study along different age boundaries might have yielded different results. Although surprising, this finding was not totally unexpected. Some authors have suggested that women within the age range of our middle group face multiple stressors in their personal and professional lives, (Johansson et al., 2010; Remennick, 1999; Riley \& Bowen, 2005) thus creating a potential for instability and psychological stress. However, stress does not necessarily translate into anger. Even those individuals who process stress maladaptively at various times may find outlets for their stress through other psychological or behavioral problems such as depression, anxiety, and substance abuse among others.

We found that the covariates (education, employment, relationship status, and country of residence) did not have any significant effects on the dependent variables. The similarities in the participants across these covariates might have contributed to the lack of effect. For instance, our sample was rather homogenous primarily being White $(83 \%)$, educated (93\% some college or above) and employed ( $74 \%$ either part- or full-time). As we previously noted, cultural norms and display rules influence the way people express emotions in general and anger in particular across various cultures or nationalities. However, in this study we did not assess for 
differences in cultural background, but rather focused on "country of residence", which does not necessarily imply a different cultural background. Also, we suggest that the cultural differences in this relative homogenous sample of women residing in urban areas of two predominantly Western-culture societies (i.e., Canada and the United States) would be rather small (if present at all), and would not have had an effect on the experience and expression of anger. Perhaps a more diverse sample with contrasting alternatives such as women from countries rooted in Asian culture and women from countries rooted in Western culture could yield different results.

\section{Conclusions}

In summary, our findings suggest differences in the effect of age on participants' experience and expression of anger, while controlling for covariates of education, employment status, and relationship status, and country of residence. Based on our findings we are compelled to reject null hypotheses 1,2, and 4. The older group had significantly lower scores than the middle group (T-Ang/T, S-Ang and S-Ang/F, AC-O, and AX-O) and the younger group $(\mathrm{S}-\mathrm{Ang} / \mathrm{F})$. As there were no significant differences in the anger expression scores among the three groups, null hypothesis \#3 was supported. Our research yielded mixed results insofar as it was the middle group (and not the younger group) that had higher levels of state and trait anger-temperament and higher frequency of outward expression of anger, despite higher attempts to control such expression. On the other hand, the overall direction of the older group's scores supports the work of other researchers on emotional regulation and age, who have suggested that as people age they report fewer interpersonal conflicts and respond to those conflicts with less stress and better emotional regulation. This study also has limitations that limit the generalizability of the study and that caution the reader when interpreting the results of our research.

\subsection{Limitations}

The limitations of our study relate primarily to our sampling strategy and the online process we used for the study. This included recruiting participants primarily from local colleges and universities, and the use of a snowball non-randomized and non-probability sampling. Other limitations to be considered include the nature of the vignette, the use of self-report measures, and the size and constitution of the sample. There were sample size differences in the number of participants in the older group $(n=49)$ vis-a-vis the younger $(n=96)$ and middle groups $(\mathrm{n}=94)$. Although we made an effort to recruit equal number of participants, perhaps the fact that the study was advertised as research on "women's anger" and was conducted online might have influenced some who might have decided for or against participating in the study due to those factors. The online nature of the study in itself might have dissuaded older participants who might not have been as familiar or felt comfortable with the technology or the online process. This might have had an effect on the smaller number of participants in the older group. Likewise, our recruitment strategy focused primarily on recruiting participants from local urban colleges and universities which might have contributed to the slant of the educational status of the participants as well as to the overall homogeneity of the sample. Also, one must consider that, whenever self-report measures are used, there is the possibility that some respondents may respond in ways they deem to be socially desirable rather than reflecting their true feelings. Finally, the content of the vignette also needs to be considered. Although Averill (1982) suggested that women tend to experience anger within the context of interpersonal relationships $79 \%$ of the time, the content of this particular vignette (i.e., an interpersonal conflict between a married couple) might not have been meaningful to all participants and therefore it might have elicited different intensity levels of anger response among the participants. Cox et al. (2004) have suggested that women may use different anger diversion styles, depending on the context of the anger-inducing situation.

\subsection{Recommendations}

We feel that despite the limitations the results of our research augment the limited data available on the effects of age on women's anger, by providing information on age differences in the experience and expression of anger for the women in this sample. However, many questions remain regarding not only the forces that contribute to the experience and expression of anger in women, but also to the variations in preferences for types of anger expression. A number of questions could be addressed in future studies. For example, how would differences in cultural norms and display rules among women impact upon how they experience or express anger? Could the differences that we found among the groups be influenced by the socialization process that discourages the direct expression of anger in women? Could such differences be related to the level of stress the women were experiencing at that particular point in their lives? Or, could they be the result of the idiosyncratic meaning that participants might have attached to the vignette? Or, as some authors have suggested, is this simply the result of learning to adapt and to pick one's battles more judiciously? In future studies researchers could address these and other questions to assess the impact of variables such as culture, religious background and participants' current stress levels on anger experience and expression. The sample of our study was slanted toward white, employed, 
and educated women. Therefore, in future studies we must consider sampling techniques that will allow for a more diverse sample of women (e.g., culture, race, socioeconomic level). Finally, since some authors have suggested that women experience increased stress and turmoil during the middle adulthood period of the 30's and 40's, perhaps future studies could more exclusively investigate that age group, in order to shed additional light on the experience and expression of anger in those women.

\section{References}

Abu-Madini, M., \& Rahim, S. (2001). Deliberate self-harm in a Saudi university hospital: A case series over six years (1994-2000). Arab Journal of Psychiatry, 12, 22-35.

Adam, H., Shirako, A., \& Maddux, W. W. (2010). Cultural variances in the interpersonal effects of anger in negotiations. Psychological Sciences, 21(6), 882-889. http://dx.doi.org/10.1177/0956797610370755

Alea, N., Bluck, S., \& Smegon, A. B. (2004). Young and Older Adults' Expression of Emotional Experience: Do Autobiographical Narratives Tell a Different Story? Journal of Adult Development, 11, 235-250. http://dx.doi.org/10.1023/B:JADE.0000044527.52470.5d

Arnett, J. J. (2000). Emerging adulthood: A theory of development from the late teens to the twenties. American Psychologist, 55, 469-480. http://dx.doi.org/10.1037//0003-066X.55.5.469

Arnett, J. J. (2004). Emerging adulthood: The winding road from the teens to the twenties. New York: Oxford University Press. http://dx.doi.org/10.1093/acprof:oso/9780195309379.001.0001

Averill. J. R. (1982). Anger and aggression: An essay on emotion. New York: Springer.

Birditt, K. S., \& Fingerman, K. L. (2005). Do we get better at picking our battles? Age group differences in descriptions of behavioral reactions to interpersonal tensions. The Journals of Gerontology, 60, 121-128. http://dx.doi.org/10.1093/geronb/60.3.P121

Birditt, K. S., Fingerman, K. L., \& Almeida, D. M. (2005). Age differences in exposure and reactions to interpersonal tensions: A daily diary study. Psychology and Aging, 20, 330-430. http://dx.doi.org/10.1037/0882-7974.20.2.330

Blanchard-Fields, F., \& Cooper, C. (2004). Social cognition and social relationships. In F. R. Lang, \& K. L. Fingerman (Eds.), Growing together: Personal relationships across the lifespan (pp. 268-289). Cambridge, England: Cambridge University Press.

Blanchard-Fields, F., Mienaltowski, A., \& Seay, R. B. (2007). Age differences in everyday problem-solving effectiveness: Older adults select more effective strategies for interpersonal problems. The Journals of Gerontology, 62B, 61-64. http://dx.doi.org/10.1093/geronb/62.1.P61

Carstensen, L. L., Pasupathi, M., Mayr, U., \& Nesselroade, J. R. (2000). Emotional experience in everyday life across the adult life span. Journal of Personality and Social Psychology, 79(4), 644-655. http://dx.doi.org/10.1037//0022-3514.79.4.644

Charles, S. T., \& Carstensen, L. L. (2008). Unpleasant situations elicit different emotional responses in younger and older adults. Psychology and Aging, 23, 495-504. http://dx.doi.org/10.1037/a0013284

Charles, S. T., \& Carstensen, L. L. (2009). Social and emotional aging. Annual Review of Psychology, 61, 383-409. http://dx.doi.org/10.1146/annurev.psych.093008.100448

Cox, D. L., Stabb, S. D., \& Bruckner, K. H. (1999). Women's anger: Clinical and developmental perspectives. Philadelphia: Brunner-Mazel.

Cox, D. L., Van Velsor, P., \& Hulgus, J. F. (2004). Who me, angry? Patterns of angry diversion in women. Health Care for Women International, 25, 872-893. http://dx.doi.org/10.1080/07399330490493412

Cox, D. L., \& St. Clair, S. (2005). A new perspective on women's anger: Therapy through the lens of anger diversion. Women \& Therapy, 28, 77- 90. http://dx.doi.org/10.1300/J015v28n02_06

Fischer, P. C., Smith, R. J., Leonard, E., Fuqua, D. R. Campbell, J. L., \& Masters, M. A. (1993). Sex differences on affective dimensions: Continuing examination. Journal of Counseling and Development, 71, 440-443. http://dx.doi.org/10.1002/j.1556-6676.1993.tb02662.x

Gilbert, D. G., Gilbert, B. O., \& Schultz, V. L. (1998). Withdrawal symptoms: Individual differences and similarities across addictive behaviors. Personality and Individual Differences, 24, 351-356. http://dx.doi.org/10.1016/S0191-8869(97)00186-4

González-Prendes, A. A. (2008). Anger-control group counseling for women recovering from alcohol or drug 
addiction. Research on Social Work Practice, 18, 616-625. http://dx.doi.org/10.1177/1049731507308356

Hatch, H., \& Forgays, D. K. (2001). A comparison of older adolescents and adult females' responses to anger-provoking situations. Adolescence, 38(143), 557-570.

Hattar-Polara, M. (2010). Developmental transitions.) In A. I. Meleis (Ed.), Transitions theory: Middle range and situation-specific theories in nursing research and practice (pp. 88-93). New York: Springer.

Johansson, L., Guo, X., Waern, M., Ostling, S., Gustafson, D., Bengtsson, C., \& Skoog, I. (2010). Midlife psychological stress and risk of dementia: A 35 year longitudinal population study. Brain: A Journal of Neurology, 133, 2217-2224. http://dx.doi.org/10.1093/brain/awq116

Kamarck, T. W., Haskett, R. F., Muldoon, M., Flory, J. D., Anderson, B., Bies, R., Pollock, B., \& Manuck, S. B. (2009). Citalopram intervention for hostility: Results of a randomized clinical trial. Journal of Consulting and Clinical Psychology, 77(1), 174-188. http://dx.doi.org/10.1037/a0014394

Konwar, N., \& Ram, U. (2004). Cultural differences in anger. Psychological Studies, 49(2-3), 193-195.

Kövecses, Z. (2000). The concept of anger: Universal or culture specific? Psychopathology, 33, 159-170. http://dx.doi.org/10.1159/000029139

Kövecses, Z. (2010). Cross-cultural experience of anger. In M. Potegal, G. Stemmler, \& C. Spielberger (Eds.), International handbook of anger: Constituent and concomitant biological, psychological, and social problems (pp. 157-174). New York: Springer. http://dx.doi.org/10.1007/978-0-387-89676-2

Labouvie-Vief, G., Hakim-Larson, J., \& Hobart, C. J. (1987). Age, ego level, and the life-span development of coping and defense processes. Psychology and Aging, 2, 286-294. http://dx.doi.org/10.1037/0882-7974.2.3.286

Labouvie-Vief, G., Hakim-Larson, J., DeVoe, M., \& Schoeberlein, S. (1989). Emotions and self-regulation: A life span view. Human Development, 32, 279-299. http://dx.doi.org/10.1159/000276480

Larimer, M. E., Palmer, R. S., \& Marlatt, G. A. (1999). Relapse prevention: An overview of Marlatt's cognitive-behavioral model. Alcohol Research and Health, 23, 151-160.

Levinson, D. J. (1978). The season's of a man's life. New York: Knopf.

Levinson, D. J., \& Levinson, J. D. (1996). The seasons of a woman's life. New York: Knopf.

Matsumoto, T., Yamaguchi, A., Chiba, Y., Asami, T., Iseki, E., \& Hirayasu, Y. (2004). Patterns of self-cutting: A preliminary study on differences in clinical implications between wrist and arm-cutting using a Japanese juvenile detention sample. Psychiatry and Clinical Neurosciences, 58, 377-382. http://dx.doi.org/10.1111/j.1440-1819.2004.01271.x

Matsumoto, D., Hee Yoo, S., \& Chung, J. (2010). The expression of anger across culture. In M. Potegal, G. Stemmler, \& C. Spielberger (Eds.), International handbook of anger: Constituent and concomitant biological, psychological, and social problems (pp. 125-137). New York: Springer. http://dx.doi.org/10.1007/978-0-387-89676-2

Mertler, C. A., \& Vannatta, R. A. (2005). Advanced and Multivariate Statistical Methods (3rd ed.). Los Angeles, CA: Pyrczak Publishing.

Meyer, C., Leung, N., Waller, G., Perkins, S., Paice, N., \& Mitchell, J. (2005). Anger and bulimic psychopathology: Gender differences in non-clinical group. International Journal of Eating Disorders, 37, 69-71. http://dx.doi.org/10.1002/eat.20038

Mitchell, V. (2011). Who Am I Now? Using life span theories in psychotherapy in late adulthood. Women \& Therapy, 32, 298-312. http://dx.doi.org/10.1080/02703140902851930

Minick, P., \& Gueldner, S. H. (1995). Patterns of conflict and anger in women sixty years of age or older: An interpretive study. Journal of Women \& Aging, 7, 71-84.

Mroczek, D. K. (2001). Age and emotion in adulthood. Current Directions in Psychological Sciences, 10, 87-90. http://dx.doi.org/10.1111/1467-8721.00122

Mroczek, D. K., \& Kolarz, C. M. (1998). The Effect of Age on Positive and Negative Affect: A Developmental Perspective on Happiness. Journal of Personality and Social Psychology, 75, 1333-1349. http://dx.doi.org/10.1037/0022-3514.75.5.1333

Mroczek, D. K., \& Almeida, D. M. (2004). The effect of daily stress, personality, and age on daily negative 
affect. Journal of Personality, 72, 355-378. http://dx.doi.org/10.1111/j.0022-3506.2004.00265.x

Munhall. P. (1993). Women's anger and its meaning: A phenomenological perspective. Health Care for Women International, 14, 481-491. http://dx.doi.org/10.1080/07399339309516078

Phillips, L. H., Henry, J. D., Hosie, J. A., \& Milne, A. B. (2006). Age, anger regulation and well-being. Aging and Mental Health, 10, 250-256. http://dx.doi.org/10.1080/13607860500310385

Phillips, L. H., Henry, J. D., Hosie, J. A., \& Milne, A. B. (2008). Effective Regulation of the Experience and Expression of Negative Affect in Old Age. Journal of Gerontology, 63B, 138-145. http://dx.doi.org/10.1093/geronb/63.3.P138

Potegal, M., \& Novaco, R. W. (2010). A brief history of anger. In M. Potegal, G. Stemmler, \& C. Spielberger (Eds.), International handbook of anger: Constituent and concomitant biological, psychological, and social problems (pp. 9-24). New York: Springer. http://dx.doi.org/10.1007/978-0-387-89676-2

Ricca, V., Castellini, G., Lo Sauro, C., Ravaldi C., Lapi T., Mannucci E., Rotella C. M., \& Faravelli, C. (2009). Correlations between binge eating and emotional eating in a sample of overweight subjects. Appetite, 53, 418-431. http://dx.doi.org/10.1016/j.appet.2009.07.008

Remennick, L. I. (1999). Women of the "sandwich" generation and multiple roles: The case of Russian immigrants of the 1990s in Israel. Sex Roles, 40, 347-378. http://dx.doi.org/10.1023/A:1018815425195

Riley, L. D., \& Bowen, C. (2005). The sandwich generation: Challenges and coping strategies of multigenerational families. The Family Journal, 13, 52-58. http://dx.doi.org/10.1177/1066480704270099

Robert, S. A., \& Reither, E. N. (2004). A multilevel analysis of race, community disadvantage, and body mass index among adults in the US. Social Science \& Medicine, 59, 2421-2434. http://dx.doi.org/10.1016/j.socscimed.2004.03.034

Sharkin, B. S. (1993). Anger and gender: Theory, research, and implications. Journal of Counseling and Development, 71, 366-379. http://dx.doi.org/10.1002/j.1556-6676.1993.tb02653.x

Spielberger, C. D. (1999). Manual for the State Trait Anger Expression Inventory-2, STAXI-2. Odessa, FL: PAR.

Stone, A. A., Schwartz, J. E., Broderick, J. E., \& Deaton, A. (2010). A snapshot of the age distribution of psychological well-being in the United States. Proceedings of the National Academy of sciences, 107, 9985-9990. http://dx.doi.org/10.1073/pnas.1003744107

Tabachnick, B. G., \& Fidel, L. S. (1996). Using multivariate statistics (3rd ed.). New York: HarperCollins Publishers.

Thomas, S. P. (1989). Gender differences in anger expression: Health implications. Research in Nursing and Health, 12, 389-398. http://dx.doi.org/10.1002/nur.4770120609

Thomas, S. P. (2002). Age differences in anger frequency, intensity, and expression. Journal of the American Psychiatric Nurses Association, 8, 44-50. http://dx.doi.org/10.1067/mpn.2002.124412

Thomas, S. P. (2005). Women's anger, aggression, and violence. Health Care for Women International, 26 , 504-522. http://dx.doi.org/10.1080/07399330590962636

Warren-Findlow, J. (2006). Weathering: Stress and heart disease in African American women living in Chicago. Qualitative Health Research, 16(2), 221-237. http://dx.doi.org/10.1177/1049732305278651

Webb, M. S., \& Beckstead, J. W. (2005). Stress-related influences on blood pressure in African American women. Research in Nursing and Health, 25, 383-393. http://dx.doi.org/10.1002/nur.10053

\section{Appendix}

Vignette

Three weeks ago Jennifer made reservations at an exclusive Italian restaurant for her and her husband Jim to have a quiet, romantic evening dinner to celebrate their wedding anniversary. She did not tell Jim as she wanted to surprise him. However, she reminded him of their upcoming anniversary and that perhaps they should do "something special". Jim has indicated that he has cleared his schedule and will be home early on that day. Jennifer feels that Jim has been spending a lot of time at work and that has taken away from the time that they would spend with each other. She is excited and looking forward to this dinner and she sees this as an opportunity to rekindle their interest in each other. On the day of the dinner, at 4 PM, Jim calls Jennifer and tells her that he has been given 
a project with a very important company and that there is no way that he can get out of it; so he is going to be late. He reassures her that they will do something on the weekend to celebrate their anniversary.

\section{Copyrights}

Copyright for this article is retained by the author(s), with first publication rights granted to the journal.

This is an open-access article distributed under the terms and conditions of the Creative Commons Attribution license (http://creativecommons.org/licenses/by/3.0/). 